\title{
Heat Storage Calculation Model for Supercritical Once-through Boilers
}

\author{
QIN Zhiming*, GU Junjie and ZHANG Luanying \\ MOE's Key Lab of Condition Monitoring and Control for Power Plant Equipment \\ North China Electric Power University, Baoding 071003 China \\ zhimingqin@163.com
}

Keywords: Supercritical once-through boiler Heat-surface Heat energy storage

Abstract. According to the properties of water and steam, The evaporating surface of supercritical once-through boiler is divided into a cold-water section, a density-change section and a overheatsteam section for both supercritical and subcritical pressures. A lumped-parameter mathematical model was build up for the steam generator,separator, over-heater through mechanism analysis and model simplification, the heat energy storage under different loads is calculated based on the design data of boiler structure. Application results on a $1000 \mathrm{MW}$ unit show that the variation of heat energy storage of the water/steam in risers under subcritical pressures is more than supercritical pressures, the metal's heat storage is much larger than the water/steam's, the over-heater's heat storage accounted for about $70 \%$ of the entire boiler's, The heat storage of boiler decreases with the pressure increasing.

\section{Introduction}

Due to the high boiler efficiency and the low pollution emission, ultra supercritical power generation has become a dominant technology in coal-fired power plants. It is also an important clean coal power generation technology for the sustainable development of power industry in China [1].

Different with subcritical units, the main steam flow or feed water flow is usually used as the correction signal of fuel calorific value in the coordinated control of supercritical units, but the signals do not have dynamic compensation of the pressure differential and then can not reflect the change of the main steam enthalpy, therefore, the input and output of boiler energy imbalance was enlarged and cause the fluctuation of pressure, temperature and loads. Due to the difference on structure, the heat storage of once-through boiler is about $1 / 3 \sim 1 / 2$ of the drum boilers' , However, the rational application of heat storage not only reduce the fluctuation of turbine inlet pressure, but also accelerate the adjustment of boiler coal flow and ensure the loads response speed, hence it is necessary for the supercritical boiler heat storage can be analyzed and calculated in details.

\section{Mechanism Analysis}

The heat storage energy of the whole boiler is the sum of working substance and the metals' in the evaporating heating surface[2]. The working substance include super cool water, saturated water, saturated steam and super-heated steam, which density and specific enthalpy varies with change in temperature and pressure, the heat storage energy of the working substance is

$$
\Delta Q_{\mathrm{g}}=V_{\mathrm{g}} \frac{\mathrm{d}}{\mathrm{d} t}\left(\rho_{\mathrm{g}} h_{\mathrm{g}}\right)
$$

where $V, \rho$ and $h$ is volume, density and specific enthalpy respectively, the subscript $g$ is for the working substance.

For metals, it absorbs or release energy when its temperature changed. The heat storage energy of the metals is

$$
\Delta Q_{\mathrm{m}}=M C_{\mathrm{p}} \frac{\mathrm{d} T_{\mathrm{m}}}{\mathrm{d} t}
$$


where $M, C_{\mathrm{p}}, T$ is the metal's quality, specific heat at constant pressure and temperature, the subscript $m$ is for metal.

According to the Boiler Thermal Calculation Standard, if the wall temperature of boiler's heating surface under rated operating conditions, then the wall temperature can calculated as follow

$T_{\mathrm{m}}=T_{\mathrm{g}}+\mu q_{\mathrm{m}}\left(\frac{\delta}{\lambda} \frac{\beta}{1+\beta}+\frac{1}{\alpha_{2}}\right)$,

where $T_{\mathrm{g}}$ is the temperature of the working substance, $\beta$ is the ratio of the outer and inner diameter of the water wall, $q_{\mathrm{m}}$ is the heat load of the water wall, $\mu$ is the current balance coefficient, $\delta$ is the thickness of water wall, $\lambda$ is the thermal conductivity of water wall, $\alpha_{2}$ is the heat transfer coefficient in water wall.

If the working substance is water, steam water mixture or over heated steam under supercritical pressure, the heat transfer coefficient $\alpha_{2}$ is large enough, so $1 / \alpha_{2}$ is negligible in the heat transfer calculation [3].

The quality of one of section of risers is $M=2 \pi r \cdot \delta \cdot l \cdot \rho$, it's heated area is $F=\pi r \cdot l$, here $r$ is the inner radius. The heat storage energy of the section is

$$
\Delta Q_{\mathrm{m}}=M C_{\mathrm{p}} \frac{\mathrm{d} T_{\mathrm{g}}}{\mathrm{d} t}+\frac{\beta}{1+\beta} \cdot \frac{2 \mu C_{\mathrm{p}} \rho \delta^{2}}{\lambda} \frac{\mathrm{d} Q_{\mathrm{m}}}{\mathrm{d} t}=M C_{\mathrm{p}} \frac{\mathrm{d} T_{\mathrm{g}}}{\mathrm{d} t}+k_{m} \frac{\mathrm{d} Q_{\mathrm{m}}}{\mathrm{d} t}
$$

Where $\delta, \beta, \rho$ and $C_{\mathrm{p}}$ is constant, $\mu$ and $\lambda$ is variable, which can regard as constant under certain working condition. Where $M C_{\mathrm{p}} \frac{\mathrm{d} T_{\mathrm{g}}}{\mathrm{d} t}$ is the variation of metal heat storage as the working condition changes, $k_{\mathrm{m}} \frac{\mathrm{d} Q_{\mathrm{m}}}{\mathrm{d} t}$ is the variation of metal heat storage as the fuel changes, it mainly presents on the dynamic response time of the combustion system.

\section{The Heat Storage of Evaporating Surface}

The Model of Evaporating Surface. Different with the drum boilers, The furnace of the once-through boiler incorporate relatively small bore evaporator tubes which are generally arranged in a spiral fashion in the lower water wall and in a vertical way in the upper water wall, and the mixed headers are installed between the upper and the lower water wall. the once-through boilers are characterized by continuous flow paths from the evaporator inlet to the superheater outlet without a separation drum in the circuit, the evaporate ending point in the water wall is moved with the load changes. At present, The maximum specific heat point ( quasi-critical point) or the critical specific volume is generally used as the divide criterion between the water region and steam region in the evaporating surface under the supercritical pressure. The mathematical model of the water wall is described as III-parts under subcritical pressure and II-parts under supercritical pressure, when the boiler is operated from subcritical to supercritical, the problem of model switching is inevitably.

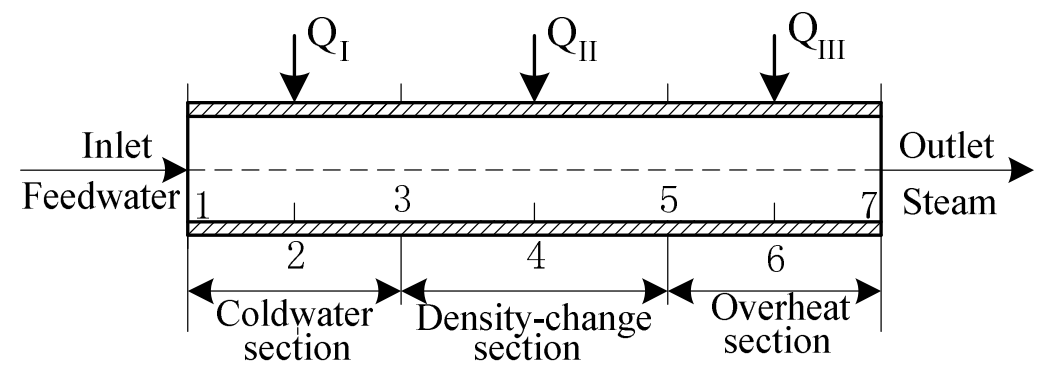

Fig.1 Schematic diagram of steam generator 
Schematic diagram of steam generator is shown in Fig.1, node1, node3, node5 and node7 are the inlet of cold-water section, the boundary of cold-water and density change section, the boundary between density change section and overheat steam section, the outlet of overheat steam section respectively. node2, node 4 and node 6 represents the lumped parameter of the cold-water section, the density-change section and the overheat-steam section[4]. The density-change section is the whole wet steam section under subcritical pressures, dryness $x_{4}=0.5$ is represent the lumped parameter in this section. The boundary of each section is moved in the dynamic process, the length of each section (cold-water section $l_{13}$, density-change section $l_{35}$, overheat-steam section $l_{57}$ ) as variable substituted into the dynamic equations[5].

The dynamic evaporating equations of conservation of energy and mass as follows:

cold-water section:

$A \frac{\mathrm{d}}{\mathrm{d} t}\left(\rho_{2} l_{13}\right)=D_{1}-D_{3}+A \rho_{3} \frac{\mathrm{d} l_{13}}{\mathrm{~d} t}$

$A \frac{\mathrm{d}}{\mathrm{d} t}\left(\rho_{2} u_{2} l_{13}\right)=D_{1} h_{1}-D_{3} h_{3}+Q_{\mathrm{I}}+A \rho_{3} h_{3} \frac{\mathrm{d} l_{13}}{\mathrm{~d} t}$

density-change section:

$A \frac{\mathrm{d}}{\mathrm{d} t}\left(\rho_{4} l_{35}\right)=D_{3}-D_{5}-A \rho_{3} \frac{\mathrm{d} l_{13}}{\mathrm{~d} t}+A \rho_{5} \frac{\mathrm{d} l_{15}}{\mathrm{~d} t}$

$A \frac{\mathrm{d}}{\mathrm{d} t}\left(\rho_{4} u_{4} l_{35}\right)=D_{3} h_{3}-D_{5} h_{5}+Q_{\mathrm{II}}-A \rho_{3} h_{3} \frac{\mathrm{d} l_{13}}{\mathrm{~d} t}+A \rho_{5} h_{5} \frac{\mathrm{d} l_{15}}{\mathrm{~d} t}$

overheat-steam section:

$A \frac{\mathrm{d}}{\mathrm{d} t}\left(\rho_{6} l_{57}\right)=D_{5}-D_{7}-A \rho_{5} \frac{\mathrm{d} l_{15}}{\mathrm{~d} t}$

$A \frac{\mathrm{d}}{\mathrm{d} t}\left(\rho_{6} u_{6} l_{57}\right)=D_{5} h_{5}-D_{7} h_{7}+Q_{\mathrm{III}}-A \rho_{5} h_{5} \frac{\mathrm{d} l_{15}}{\mathrm{~d} t}$

where $u_{2}, u_{4}$ and $u_{6}$ are the internal energy of cold-water section $l_{13}$, density-change section $l_{35}$, overheat-steam section respectively, $\mathrm{kJ} / \mathrm{kg}$. $A$ is the cross-sectional area of the tube, $\mathrm{m}^{2} . D_{i}$ is the mass flow of water (steam) for each node, $\mathrm{kg} / \mathrm{s}$.

Assume that the flow in each section of the water wall is constant, the follows can be derived from eq. 5 ,eq. 7 and eq. 9 .

$\frac{\mathrm{d} l_{13}}{\mathrm{~d} t}=\frac{l_{13}}{\rho_{3}-\rho_{2}} \frac{\mathrm{d} \rho_{2}}{\mathrm{~d} t}$

$\frac{\mathrm{d} l_{35}}{\mathrm{~d} t}=\frac{1}{\rho_{4}}\left(-\rho_{3} \frac{\mathrm{d} l_{13}}{\mathrm{~d} t}+\rho_{5} \frac{\mathrm{d} l_{15}}{\mathrm{~d} t}-l_{35} \frac{\mathrm{d} \rho_{4}}{\mathrm{~d} t}\right)$

$\frac{\mathrm{d} l_{57}}{\mathrm{~d} t}=-\frac{l_{57}}{\rho_{6}-\rho_{5}} \frac{\partial \rho_{6}}{\partial p_{6}} \frac{\mathrm{d} p_{6}}{\mathrm{~d} t}$

$\rho u=p-\rho h$

eq.11 eq.14 are substituted into eq.6, eq. 8 and eq.10, the working substance heat storage in cold-water section $\Delta Q_{\mathrm{I}}$, density-change section $\Delta Q_{\mathrm{II}}$ and overheat steam section $\Delta Q_{\mathrm{III}}$ can be deduced.

$$
\begin{aligned}
& \Delta Q_{\mathrm{I}}=\left[\left(p_{2}-\rho_{2} h_{2}\right) \frac{d l_{13}}{d t}+l_{13}\left(1-h_{2} \frac{\partial \rho_{2}}{\partial p_{2}}-\rho_{2} \frac{\partial h_{2}}{\partial p_{2}}\right)\right] \frac{\mathrm{d} p_{2}}{\mathrm{~d} t} \\
& \Delta Q_{\mathrm{II}}=\left(p_{4}-\rho_{4} h_{4}\right) \frac{\mathrm{d} l_{35}}{\mathrm{~d} t}+l_{35}\left(1-\rho_{4} \frac{\partial h_{4}}{\partial p_{4}}-h_{4} \frac{\partial \rho_{4}}{\partial p_{4}}\right) \frac{\mathrm{d} p_{4}}{\mathrm{~d} t} \\
& \Delta Q_{\mathrm{III}}=\left(p_{6}-\rho_{6} h_{6}\right) \frac{\mathrm{d} l_{57}}{\mathrm{~d} t}+l_{57}\left(1-h_{6} \frac{\partial \rho_{6}}{\partial p_{6}}-\rho_{6} \frac{\partial h_{6}}{\partial p_{6}}\right) \frac{\mathrm{d} p_{6}}{\mathrm{~d} t}
\end{aligned}
$$


Calculation model of specific enthalpy. the water wall tube rise from the bottom of furnace in spiral fashion, each tube almost hundred meters, To simplify the calculations make the following assumptions:

(1) Each water wall tube cross section has evenly fluid properties and equal flow.

(2) the furnace envelope can be seen as a cuboid, the cross section of upper section and lower section has the same perimeter.

(3) the total flow through the cross section of the working substance is equal.

(4) flue gas parameters evenly distribute along the cross section of furnace, the distribution of heating surface radiant heat intensity as shown in [6] and [7].

One element which height $\mathrm{d} x$ is derived from the height $x$ of the furnace, it's heat absorption is $\mathrm{d} Q=q_{x} L \mathrm{~d} x$

$q_{x}=q \sum_{i=0}^{6} c^{i}\left(\frac{x}{H}\right)^{i}$

Where $L$ is the perimeter of the element's cross section, m. $q_{x}$ is the average heat load at the height $x$ of the furnace, $\mathrm{KW} / \mathrm{m}^{2} . q$ is the average heat load of the evaporating surface, $\mathrm{KW} / \mathrm{m}^{2} . H$ is the height of furnace. $c_{\mathrm{i}}$ is the distribution heat absorption coefficient matrix in the furnace [8].

At the height $x$ of the furnace, the heat absorption of working substance in water wall is

$Q_{x}=D\left(h_{x}-h_{i n}\right)$

where $D$ is the mass flow of working substance in water wall, $\mathrm{kg} / \mathrm{s} . h_{\text {in }}$ is the specific enthalpy of evaporating tube inlet, $\mathrm{kJ} / \mathrm{kg} . h_{x}$ is the specific enthalpy at the height $x$ of the furnace, $\mathrm{kJ} / \mathrm{kg}$.

Eq.19 for $x$ derivative at both ends, and integrate with furnace height as boundary conditions[9],

$h_{x}=h_{\text {in }}+0.9373\left(h_{\text {out }}-h_{\text {in }}\right) \sum_{i=0}^{6} \frac{c_{i}}{i+1}\left(\frac{x}{H}\right)^{i+1}$

Calculation model of Pressure Reducing. when the fluid flows in the tube, the pressure reduced by friction, local resistance, gravity and acceleration. on the evaporating surface the pressure reduced mainly by friction and gravity .

In the single phase flow tube, the reduced pressure at the height $x$ of the furnace is

$\Delta p=\left(\frac{\lambda \rho u^{2}}{2 d}+\rho g\right) h_{x}=\left(\frac{\lambda}{2 \rho d}\left(\frac{D}{n F}\right)^{2}+\rho g\right) h_{x}$

where $\lambda$ is the friction coefficient, $d$ is the Inside diameter of evaporating tube, m. $\rho$ is the average density of the working substance, $\mathrm{kg} / \mathrm{m}^{3} . F$ is the flow area of the water wall, $\mathrm{m}^{2} . n$ is the number of tubes on the water wall, $g$ is the acceleration of gravity, $\mathrm{m} / \mathrm{s}^{2}$.

In steam liquid two phase flow tube under subcritical pressure, the reduced pressure is $\Delta p_{\mathrm{tp}}=\phi_{\mathrm{LO}}^{2} \Delta p_{\mathrm{LO}}$

where $\Delta p_{t p}$ is the reduced pressure of steam-water friction, $\phi_{\mathrm{LO}}^{2}$ is the reduced pressure ratio of steam- water friction, acquired by experiment[9], $\Delta p_{\mathrm{LO}}$ is the reduced pressure of single phase water.

\section{Calculation and Analysis}

Take one 1000 MW supercritical once through boiler as the research object, which produced by Dongfang Boiler Group, DG3000/26.15 - III. The rifle evaporator tubes which are arranged in a spiral fashion in the lower water wall, The smooth evaporator tubes which are arranged in a vertical way in the upper water wall.

According to the specific enthalpy and reduced pressure model on the evaporating surface, the specific enthalpy and pressure of working substance along with the height of furnace can be work out, 
the height of cold-water section,density-change section and overheat-steam section cam be calculated by the boundary equations of IAPWS-97, the distribution of each section along with the furnace under different loads as shown in Fig.4. When the power generation unit runs under subcritical or supercritical the majority working substance of evaporating surface in a status of density-change. when the unit loads changes from 30\% BMCR (boiler maximum continuous rating) to 50\% THA (turbine heat-rate acceptance power), the running pressure decreased under subcritical, part of supercooled water will vaporize into saturated water,at the same time part of saturated steam will vaporize into overheat steam, hence the volume of the cold-water section and overheat-steam section increases as the unit loads increase. When the pressure higher than $16.529 \mathrm{MPa}$, the boundary conditions changed between regions, that is, the unit loads changes from 50\% THA to 75\% THA, the inlet temperature of the water wall rised as the load increases, meanwhile, the outlet of the water wall should guarantees a certain degree of superheater, therefore, the volume of the cold-water section and overheat-steam section decreases as the unit loads increase. When the unit loads over $75 \%$ THA, the pressure under supercritical status, the volume of the cold-water section and overheat-steam section almost unchanged.

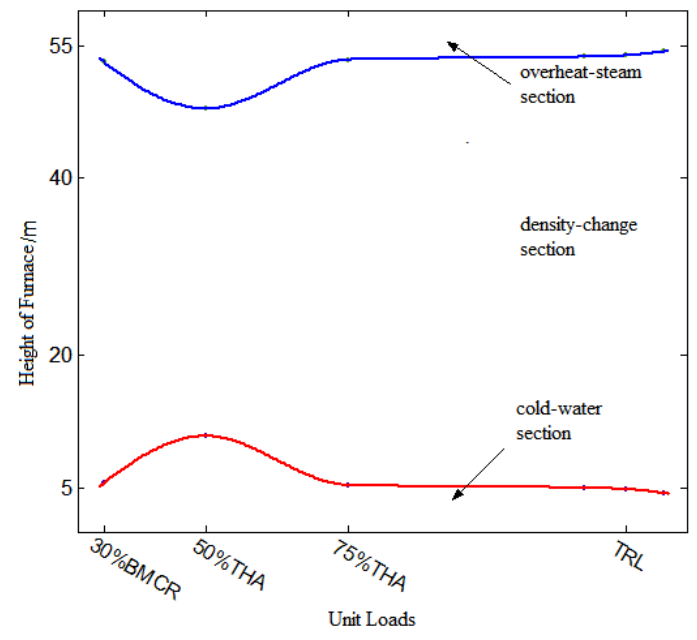

Fig.2The regions' distribution under different loads

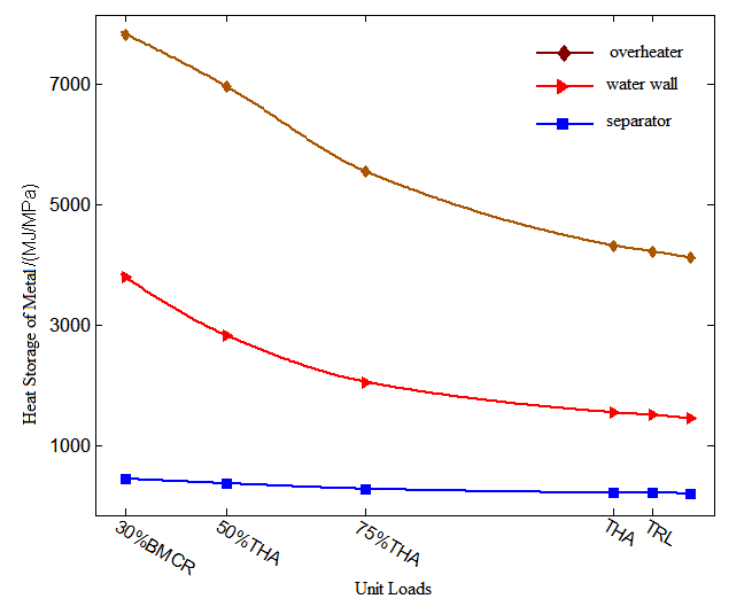

Fig.4Metal's heat-storage under different loads

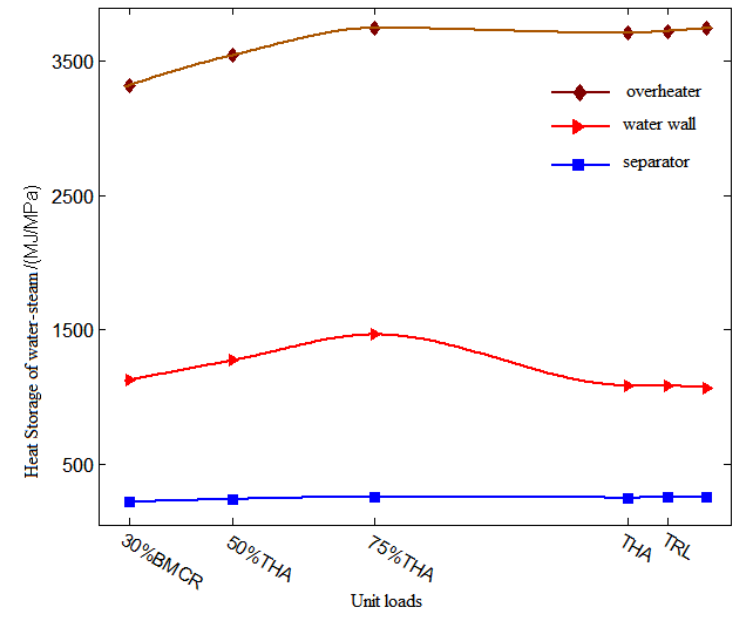

Fig.3 Water/Steam's heat storage under different loads

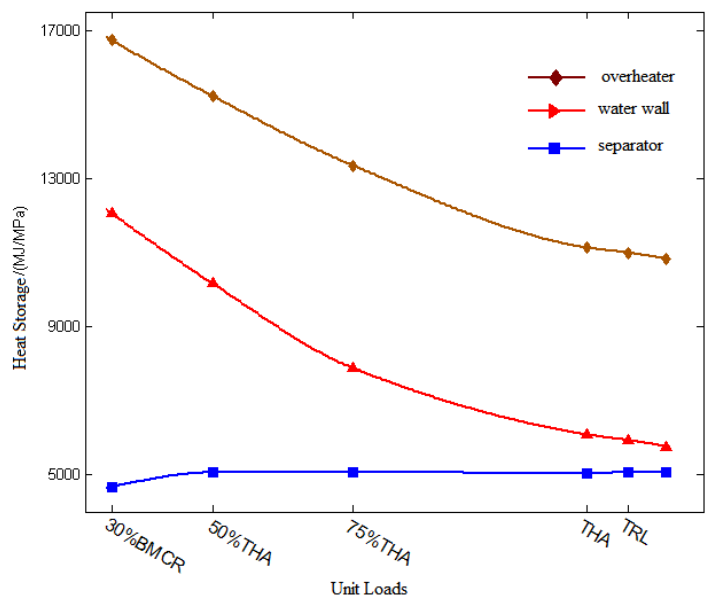

Fig.5 Boiler's heat-storage under different loads

The heat storage of working substance and metal in the water wall, separator and over heater variate with unit loads change is shown in Fig.5 and Fig.6 when the unit runs under subcritical pressure, The heat storage of working substance have the same change with pressure ,due to the rate of change between specific enthalpy and pressure, specific volume and pressure is relatively large in wet steam region. As the pressure increased, the rate of change between specific enthalpy and pressure, specific volume and pressure gradually decreased in critical region and overheat region, hence the heat storage of working substance gradually decreased under supercritical pressure.the heat 
storage of working substance in the water wall is about $1 / 3$ of the heat storage of working substance in the over heater, the power unit runs between the subcritical and supercritical will not cause the sharp change of boiler heat storage. The variation tendency of heat storage in boiler is shown in Fig.7, the metal's heat storage more than the working substance's, the boiler heat storage decrease with the pressure increase.

\section{Conclusions}

Boiler heat storage has a key role in the coordination control system, which be calculated accurately can acquire better control quality of the units in different load pressure conditions. the metal's heat storage more than the working substance's, the boiler heat storage decrease with the pressure increase.

\section{Acknowledgments}

This work was financially supported by Fundamental Research Funds for Central Universities (12MS115).

\section{References}

[1] LIU Xinping, TIAN Liang, ZHAO Zheng, et al. The quantitative analysis of the drum boiler heat storage coefficient, J. Journal of Power Engineering,2(2008)216- 220.

[2] LIU Jizhen, QIN Zhiming, ZHANG Luanying, et al. Analysis and calculation of heat storage capacity in drum boilers, J. Journal of Chinese Society of Power Engineering, 2(2012)96-100.

[3] FAN Quangui, Principles of Boiler, China Electric Power Press, beijing,2008.

[4] HUANG Jintao, CHEN Tingkuan. Dynamic characteristic of evaporating heating surface in supercritical once-through boiler, J. Xi'an Jiaotong University Xuebao, 9(1999)71-75.

[5] FAN Yongsheng, XU Zhigao, CHEN Laijiu. Modeling and simulation study on a supercritical once-through boiler steam generator I, J. Proceedings of the CSEE, 4(1998)246-253.

[6] LI Yunze, YANG Xianyong, ZHANG Yong, et al. Linear evaporation model for process of supercritical once-through boiler, J. Journal of Tsinghua University:Science and Technology, 8(2002)1117-1120.

[7] LIU Fuguo, DONG Xinguang, HOU Fanjun, et al. Static-state mathematical model of evaporating heat surface in supercritical pressure once-through boilers, J. Proceedings of the CSEE, 20(2009)12-16.

[8] LIU Fuguo. Overheating prediction of evaporating tubes in supercritical pressure once-through boiler, J. Proceedings of the CSEE, 35(2010)18-25.

[9] CHEN Tingkuan, ZHENG Jianxue, LUO Yushan, et al. A study of frictional flow resistance within internally ribbed tubes under supercritical pressure, J. Power Equipment, 4(1999)24-28. 